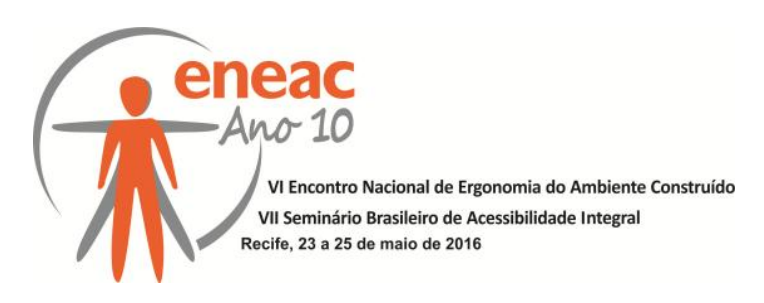

\title{
ANÁLISE DO ATENDIMENTO A PESSOA SURDA: UM ESTUDO PRELIMINAR EM UM AEROPORTO NO SUL DO BRASIL
}

\author{
LOPEZ, Monica (1); \\ VERGARA, Lizandra (2) \\ (1) Universidade Federal de Santa Catarina, Mestranda PPGEP \\ e-mail: mnikalopez@gmail.com \\ (2), Universidade Federal de Santa Catarina, Doutora em Engenharia de Produção \\ e-mail: l.vergara@ufsc.br
}

\begin{abstract}
RESUMO
Atividades cotidianas que são desempenhadas com facilidade por pessoas ouvintes podem ser para os sujeitos surdos um desafio. A comunicação é a maior barreira enfrentada por eles, embora existam leis que determinam que locais de atendimento público possuam funcionários capacitados em LIBRAS essa ainda não é uma realidade. Este artigo realizou um levantamento de dados com 15 funcionários de algumas Cias Aéreas de um Aeroporto no Sul do País, com o intuito de conhecer como estes funcionários estão sendo preparados e se estão aptos para atender a este público. Constatou-se que existe pouco treinamento e quando este é realizado não é suficiente.
\end{abstract}

Palavras chave: Aeroporto; Surdo; LIBRAS; Acessibilidade.

\begin{abstract}
The biggest barrier faced by deaf and hard of hearing is communication. Although there are laws that ensure the right of deaf people to be cared for in public services through sign language this is still not a reality. This article aimed to carry out a data survey with 15 employees of some Airlines belonging to an Airport located in southern of Brazil. It was contacted that there is a lack of training and inadequate staff training and what it takes carry out further research to find effective solutions.
\end{abstract}

Keywords: Airport; Deaf; LIBRAS; Accessibility.

\section{INTRODUÇÃO (11 PTS, NEGRITO)}

Atividades cotidianas desempenhadas com facilidade por pessoas ouvintes, como: fazer o check-in no aeroporto, pedir um taxi, ir ao banco ou a uma consulta médica, são para os sujeitos surdos um desafio. A comunicação é uma barreira para o surdo e muitas vezes faz com que ele se sinta como estrangeiro em seu próprio país. Skliar (1998, p. 51) relata, ao referir-se a educação dos surdos que "são muitos os testemunhos de surdos que, ao fazer referência a seu passado educativo, invocam a imagem de serem estrangeiros, forasteiros, exilados".

Também é possível estabelecer essa relação quando se trata do atendimento em locais que oferecem serviços públicos como o Aeroporto, aonde a maioria dos avisos é sonoro e não existe um treinamento adequado para o atendimento a pessoa surda na Língua Brasileira de Sinais (LIBRAS). Embora existam leis que determinam que os funcionários de 


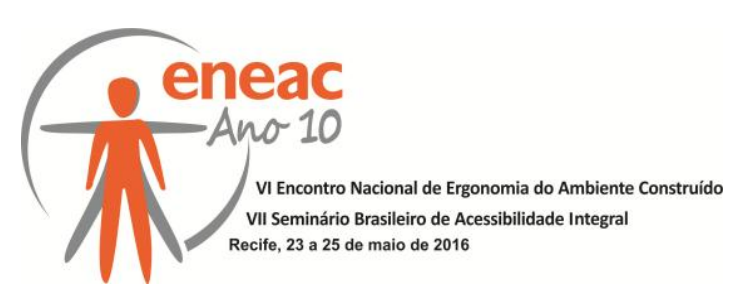

concessionárias de serviço público e órgãos de administração pública federal sejam capacitados para atender a pessoa surda, inclusive por meio da LIBRAS (Decreto de lei № 5.626 Art.25 de 22 de dezembro de 2005) esta ainda não é uma realidade no Brasil.

Chaveiro (2005, p. 418) salienta que "conviver no universo das pessoas com deficiência envolve uma mudança de paradigmas, e, para os surdos essa mudança ocorre quando são aceitos e respeitados em suas diferenças". A autora coloca também que ao contar com a presença de interpretes da LIBRAS no atendimento ao surdo é uma forma de valorizá-lo. A língua de sinais é um sistema linguístico legítimo e natural, utilizado pela comunidade brasileira surda, de modalidade gesto-visual e com estrutura gramatical independente da Língua portuguesa falada no Brasil. A Língua Brasileira de Sinais (LIBRAS) possibilita ao surdo a interação social e intelectual, permitindo o acesso ao conhecimento científico e integração interpessoal (AZEREDO, 2006). Laborit, uma atriz francesa que é surda, relata em seu livro seu sentimento quanto ao uso la linguagem de sinais.

"Recuso-me a ser considerada excepcional, deficiente. Não sou. Para mim a língua de sinais corresponde a minha voz, meus olhos são meus ouvidos. Sinceramente nada me falta. É a sociedade que me torna excepcional" (Laborit ,1994, p.83).

Entretanto um interprete de LIBRAS não resolveria totalmente o problema $o$ atendimento a pessoa surda, uma vez que existem diferenças de acordo com o grau de surdez e do tipo de linguagem aprendida (oral-auditiva, espaço-visual, ou ambas). Chaveiro et al. (2008) separou as necessidades de comunicação da pessoa surda em 3 categorias:

- Pessoas com dificuldade de audição, mas que já tiveram contato com o português e se beneficiam do código verbal;

- Pessoas surdas que se comunicam oralmente (são oralizadas) podendo ser subdivididas em dois grupos: a) adultos que perderam a audição; b) crianças que foram educadas em uma linha oralista;

- Pessoas que se comunicam pela linguagem de sinais e que perderam a audição antes dos três anos de idade, ou seja, não adquiriram a linguagem verbal e foram educadas por meio da língua de sinais.

Logo se faz necessário, além do treinamento em LIBRAS, conhecer essas particularidades e compreender qual forma de comunicação a pessoa surda se sente mais confiante para utilizar. A acessibilidade vai além de tornar um ambiente "legalmente" acessível, mas se estabelece quando há verdadeiro interesse em que todas as pessoas participem de igual forma das atividades da sociedade.

Este artigo tem como objetivo verificar se os funcionários das companhias aéreas de um Aeroporto localizado no Sul do Brasil - receberam treinamento adequado e estão aptos para atender ao usuário surdo principalmente utilizando a Linguagem Brasileira de Sinais.

\section{METODOLOGIA}

Ao buscar respostas para um problema que envolve um grupo social específico, no qual é necessário levantar informações e explorar com mais profundidade suas causas, optou-se pela pesquisa exploratória com abordagem qualitativa, utilizando como método para coleta de dados o levantamento. A pesquisa de natureza qualitativa caracteriza-se, não pela preocupação da representatividade numérica do grupo pesquisado, mas sim, pelo aprofundamento da compreensão desse grupo (GOLDENBERG, 2003). Ela é realizada de forma descritiva, por meio de interpretação de fenômenos e atribuição de significados, sendo o ambiente natural a fonte para a coleta de dados e o pesquisador é o instrumentochave (SILVA; MENEZES, 2001). 


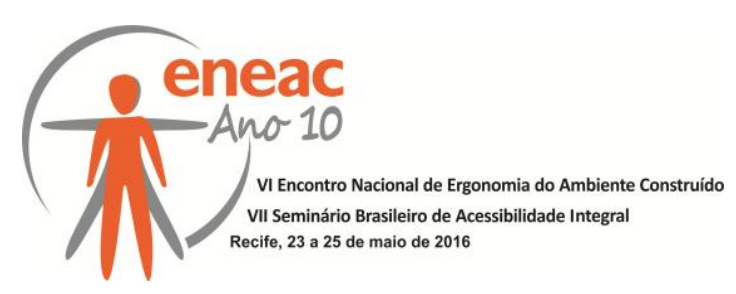

O levantamento de dados foi feito por meio de entrevista semiestruturada com 15 funcionários distribuídos entre as companhias aéreas localizadas em um Aeroporto no Sul do Brasil. As falas foram gravadas e as entrevistas foram realizadas entre os meses de agosto e setembro de 2014 e tiveram duração média de 7 minutos. A princípio foram elaboradas sete questões e foram feitas duas entrevistas com funcionários de uma companhia aérea do aeroporto e percebeu-se que seria necessário reformular as questões as vezes o pesquisador se depara com situações que não foram planejadas, por isso é importante fazer uma teste com alguns participantes e analisar se as questões respondem as perguntas levantadas pela pesquisa. Então foram elaboradas cinco novas questões, quatro abertas e uma fechada, as questões eram relacionadas a experiência do funcionário ao comunicar-se com uma pessoa surda; sobre o treinamento em LIBRAS e; a respeito das dificuldades enfrentadas durante essa comunicação.

Posteriormente as falas dos participantes foram transcritas e analisadas por meio da Análise do Conteúdo, que consiste em um conjunto de técnicas de análise das comunicações que utiliza procedimentos sistemáticos e objetivos de descrição do conteúdo. Sua intenção são as inferências de conhecimentos relativos às condições de produção ou recepção, estas podem recorrer a indicadores quantitativos ou não. Desta forma a análise de conteúdo objetiva ultrapassar as incertezas e enriquecer a leitura dos dados coletados (BARDIN, 1997). De acordo com o autor a Análise do Conteúdo é separada em três etapas: préanálise (nesta é feita a operacionalização e sistematização das ideias); exploração do material (aqui o material é codificado, categorizado e quantificado) e; o tratamento dos resultados (os dados são tratados quantitativamente, mas por meio de uma interpretação qualitativa).

Na pré-análise foi feita a leitura flutuante das entrevistas. Na sequência foi realizada a exploração do material, na qual, a priori, foram separadas as temáticas das problemáticas e depois a partir das problemáticas foram feitas duas análises descritivas: a tipológica por semelhança e a categorial.

$\mathrm{Na}$ análise tipológica por semelhança as problemáticas foram agrupadas em categorias e subcategorias que representam as situações-tipo encontradas nesta pesquisa, na figura 1 é possível visualizar um esquema sintetizado dessas categorias.

Figura 1: Síntese Análise Tipológica

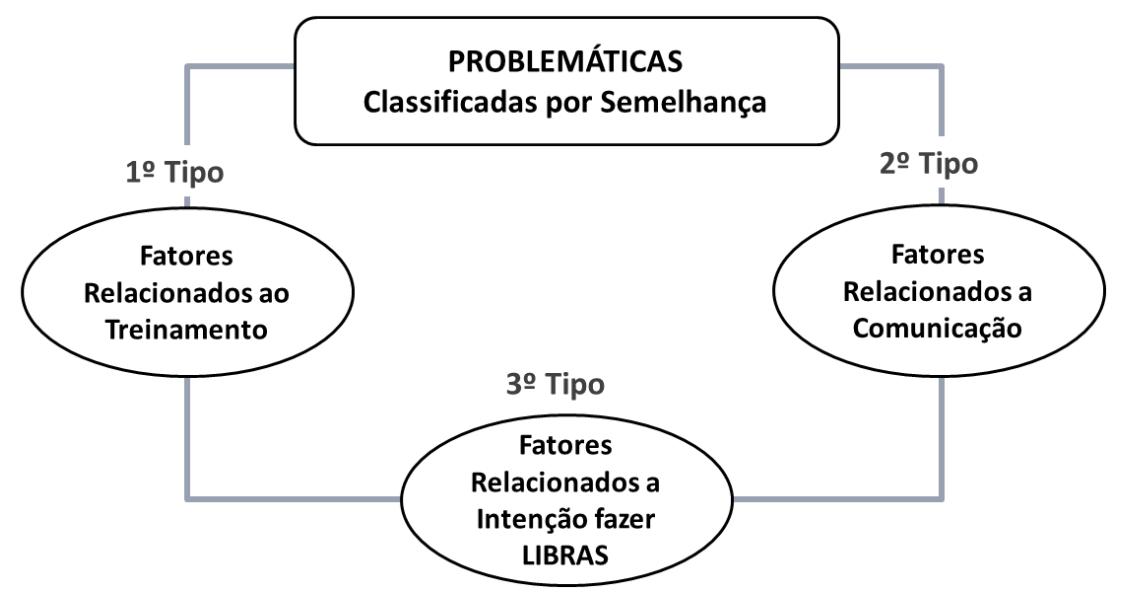

Fonte: Autora

As categorias são referentes aos: 


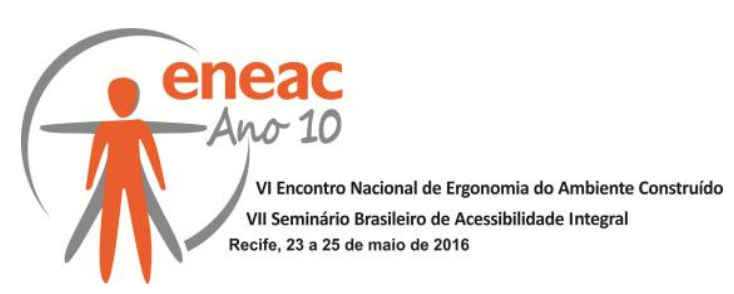

- Fatores relacionados ao treinamento: neste grupo estão listados os tipos de treinamento levantados pelas entrevistas. Que podem ser: treinamento básico específico para surdo oferecido pela companhia aérea (LIBRAS básico); treinamento modelo prioridades (para todos os tipos de deficiência) e; treinamento realizado por interesse pessoal.

- Fatores relacionados à comunicação: aqui são pontuadas as possíveis formas de comunicação que o atendente recorre ao tentar se comunicar com a pessoa surda. Sendo elas: escrita em português (trocando papéis); escrita utilizando o computador; comunicação em LIBRAS e; apontando, gesticulando ou monitorando.

- Fatores relacionados ao interesse em aprender LIBRAS: aqui procurou-se perceber se o funcionário apresentava interesse em aprender LIBRAS para melhor atender a pessoa surda, esta categoria foi dividida em duas subcategorias: a primeira refere-se a demonstração do interesse do atendente, de forma verbal e atitudinal, em fazer um curso de LIBRAS e, na segunda subcategoria, o atendente coloca uma condicionante a essa vontade, como por exemplo, o tempo.

Com as categorias formadas foi feita uma tabela que apresenta a frequência de respostas para cada categoria e subcategoria (os entrevistados estão representados como Eentrevista 1 - E1; E2...); algumas respostas interessantes foram transcritas na ultima coluna, como demonstra o exemplo simplificado na tabela 1.

Tabela 1: Análise Tipológica -Tabela de Categorias

\begin{tabular}{|c|c|c|c|}
\hline Problemática & Subcategorias & Frequência & Principais declarações dos entrevistados \\
\hline \multirow{3}{*}{$\begin{array}{c}\text { Fatores } \\
\text { relacionados ao } \\
\text { treinamento }\end{array}$} & $\begin{array}{l}\text { Treinamento básico } \\
\text { específico para } \\
\text { surdo oferecido } \\
\text { pela companhia }\end{array}$ & E3;E5;E9; E13 & $\begin{array}{l}\text { "Eu fiz o básico do básico, mas eu não lembro mais } \\
\text { nada... bem pouquinho... Foi na escola de aviação que } \\
\text { tinham algumas turmas ai eles davam .. fazia a parte do.. } \\
\text { curriculo"; "A gente faz um curso pela empresa é um } \\
\text { curso bem básico, assim. A gente aprende "bom dia, boa } \\
\text { tarde, o basicão, né". }\end{array}$ \\
\hline & $\begin{array}{l}\text { Treinamento } \\
\text { modelo prioridades } \\
\text { (para todos os tipos } \\
\text { de deficiência) }\end{array}$ & E11, E15, E16. & $\begin{array}{l}\text { "Nós temos um treinamento de prioridades da... } \\
\text { Florianópolis, né? Que abrange necessidades especiais } \\
\text { como cadeirantes, deficiências auditivas e visuais, mas } \\
\text { nenhum curso prolongado de LIBRAS, né? .. ou.. de } \\
\text { interpretação ou coisa parecida". }\end{array}$ \\
\hline & $\begin{array}{l}\text { Treinamento } \\
\text { realizado por } \\
\text { interesse pessoal }\end{array}$ & E13. & $\begin{array}{l}\text { "Eu fiz um curso de LIBRAS básico em } 2010 \text { na } \\
\text { Associação dos Surdos de Florianópolis porque eu tava } \\
\text { fazendo o curso de comissária da Gol e teve um curso } \\
\text { básico de LIBRAS aí achei interessante para ter um } \\
\text { diferencial no currículo e acabei me apaixonando, assim, } \\
\text { gostando e sempre que eu posso eu falo pra todo mundo } \\
\text { fazer porque eu acho que é realmente muito importante. E } \\
\text { agora esse ano eu faço no PRONATEC o curso básico } \\
\text { também de LIBRAS mas é pra relembrar, aprender } \\
\text { alguma coisa nova e perder a vergonha de falar com } \\
\text { alguém surdo". }\end{array}$ \\
\hline
\end{tabular}

A outra análise realizada foi a categorial, que também é um tipo de análise descritiva, contudo é mais abstrata e não é exclusiva, ou seja, em uma mesma entrevista é comum encontrar diversos fatores explicativos que não precisam se enquadrar em apenas uma categoria (como ocorre na análise tipológica), mas uma mesma resposta pode conter todas as variáveis (BARDIN, 1997). Então foi construído um esquema no qual são apresentadas todas as variáveis que incidem sobre o atendimento do usuário surdo pelos funcionários das companhias aeras que podem levar a um atendimento não satisfatório, como está representado na figura 2. 


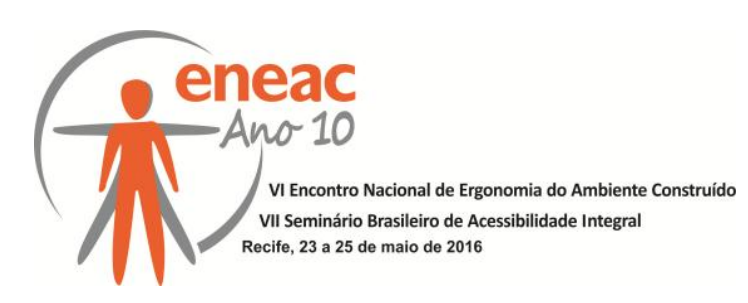

F2: Análise Categorial

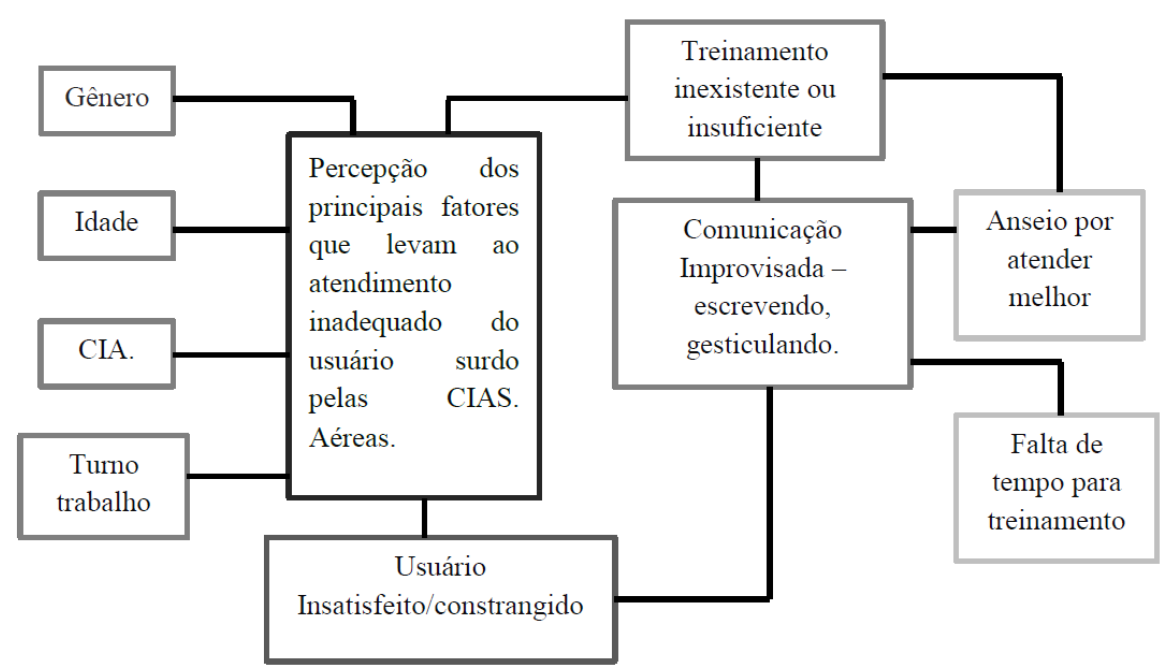

Fonte: Autora.

Finalizada a etapa de exploração do material inicia-se o tratamento dos resultados que será abordado na próxima seção desse artigo.

\section{RESULTADOS E DISCUSSÃO}

A análise do conteúdo permitiu que os dados qualitativos obtidos com as entrevistas fossem categorizados e posteriormente transformados em dados quantitativos que serão apresentados e explicados nesta seção. Primeiramente serão descritos os dados referentes ao perfil dos entrevistados (sexo, idade, tempo de trabalho, etc.); depois serão apresentados os dados levantados nas questões das entrevistas e; por ultimo a discussão sobre o tema.

\subsection{Perfil da amostra}

Dos 15 entrevistados, 9 são homens e 6 são mulheres, a maioria possui idades entre 20 e 25 anos $(46,7 \%)$ ou 26 e 35 anos (40\%). Os períodos de trabalho que tiveram maior frequência nas respostas foram: período da tarde para a noite $(26 \%)$ e período da madrugada para a manhã (26\%). Quanto ao tempo de trabalho na empresa, 46,6\% afirmaram trabalhar de 1 a dois anos e meio na empresa, os demais foram bem distribuídos entre as outras categorias (os dados completos podem ser visualizados na tabela 2).

Tabela 2: Perfil dos Funcionários

\begin{tabular}{|l|l|l|}
\hline \multicolumn{3}{|l|}{ Sexo } \\
\hline Masculino & 9 & $60 \%$ \\
\hline Feminino & 6 & $40 \%$ \\
\hline \multicolumn{2}{|l|}{ Turno Trabalho } \\
\hline Comercial & 2 & $13,3 \%$ \\
\hline M/T & 1 & $6,7 \%$ \\
\hline T/N & 4 & $26,7 \%$ \\
\hline N/Madr. & 2 & $13,3 \%$ \\
\hline Madr./M & 4 & $26,7 \%$ \\
\hline Turnos & 2 & $13,3 \%$ \\
\hline
\end{tabular}

\begin{tabular}{|c|c|c|}
\hline \multicolumn{3}{|l|}{ Idade } \\
\hline 20 a 25 & 7 & $46,7 \%$ \\
\hline 26 a 35 & 6 & $40 \%$ \\
\hline 36 a 59 & 2 & $13,3 \%$ \\
\hline \multicolumn{3}{|c|}{ Tempo de Trabalho na Empresa } \\
\hline Menos de 1 ano & 2 & $13,3 \%$ \\
\hline De 1 a 2 anos e meio & 7 & $46,7 \%$ \\
\hline De 3 a 4 anos e meio & 3 & $20 \%$ \\
\hline Mais que 5 anos & 3 & $20 \%$ \\
\hline
\end{tabular}

\subsection{Resultados Questões da Pesquisa}




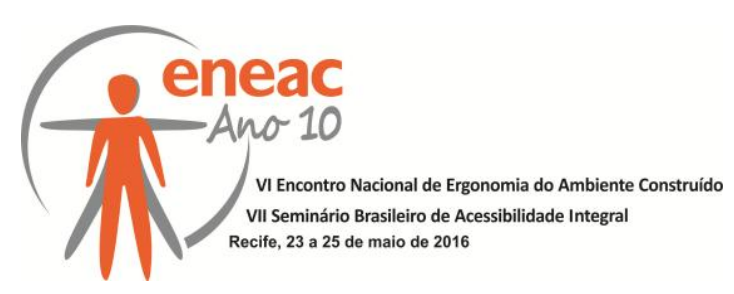

Quanto ao atendimento realizado pelo funcionário a pessoa surda foi perguntado, a princípio, se o entrevistado recebeu treinamento para atender a esse público e em seguida perguntou-se como foi esse treinamento (capacitação em LIBRAS básico, treinamento prioridades, buscou por conta própria aperfeiçoamento em LIBRAS). Costatou-se que 8 funcionários não tiveram nenhum tipo de treinamento e 7 tiveram. Sendo que 3 receberam o curso tipo prioridades, o qual não é específico para o surdo, mas para todos os tipos de deficiência; enquanto 2 tiveram um curso básico de LIBRAS no treinamento para comissário de bordo e, os outros 2 fizeram o curso em outra instiuição, sendo que apenas um deles buscou aperfeiçoamento por interesse pessoal (tabela 3).

Tabela 3: Local de Treinamento Atendimento ao Surdo

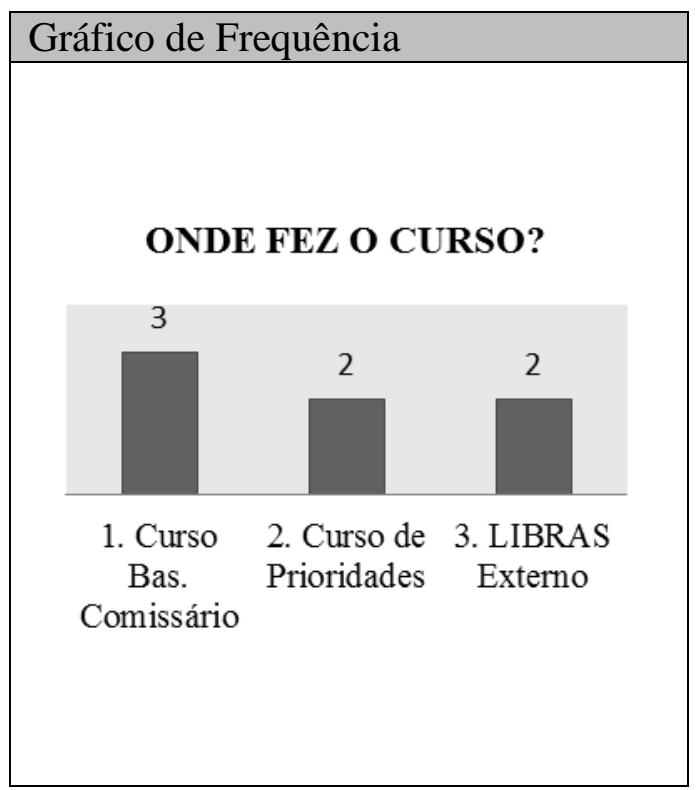

\begin{tabular}{|l|}
\hline Extrato Entrevista \\
\hline 1."Eu fiz o básico do básico, mas eu não lembro mais \\
nada... bem pouquinho... Foi na escola de aviação que \\
tinham algumas turmas aí eles davam... \\
\hline 2."Nós temos um treinamento de prioridades da... \\
Florianópolis, né? Que abrange necessidades \\
especiais como cadeirantes, deficiências auditivas e \\
visuais, mas nenhum curso prolongado de LIBRAS, \\
né?.. \\
3. "Eu fiz um curso de LIBRAS básico em 2010 na \\
Associação dos Surdos de Florianópolis porque eu \\
tava fazendo o curso de comissária da Gol e teve um \\
curso básico de LIBRAS aí achei interessante para ter \\
um diferencial no currículo e acabei me apaixonando, \\
assim, gostando e sempre que eu posso eu falo pra \\
todo mundo fazer porque eu acho que é realmente \\
muito importante....
\end{tabular}

Também foi perguntado se o funcionário já havia atendido uma pessoa surda, como foi essa experiência e que recursos ele utilizou para se comunicar, por exemplo, se foi uma conversa em LIBRAS, se escreveu em um papel ou no computador, se preferiu gesticular e apontar, etc. As respostas revelaram que a maioria dos funcionários já havia atendido uma pessoa surda (14 de 15) e também demonstraram que a maioria acaba escrevendo em português para se comunicar, seja no papel (8 participantes), ou no computador (3 participantes). Outros três participantes disseram se comunicar gesticulando, apontando ou acompanhando o surdo, e, apenas uma pessoa se comunica por meio da LIBRAS. Os depoimentos juntamente com o gráfico apresentando as frequências podem ser encontrados na tabela 4. 


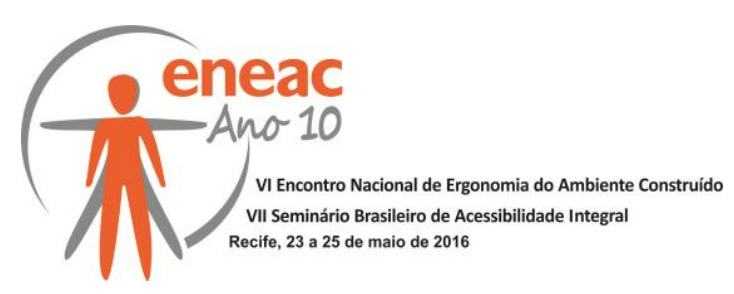

Tabela 4: Comunicação com o Usuário Surdo

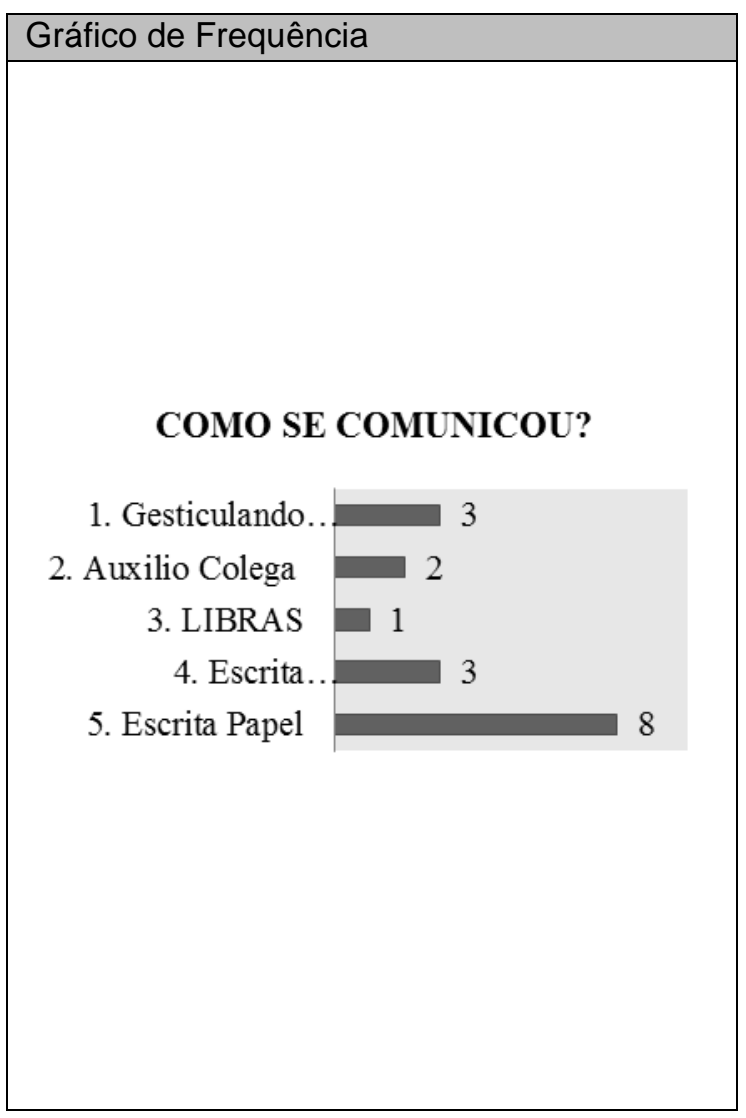

\begin{tabular}{|c|}
\hline Extrato Entrevista \\
\hline $\begin{array}{l}\text { 1. "a gente tenta de vagar... falando de vagar.. tentar } \\
\text { fazer com ele (...) algumas vezes não é possível aí } \\
\text { se der a gente tenta ler ou escrever. Aí na sala de } \\
\text { embarque, se tem um atraso de voo a gente sabe } \\
\text { que tem um deficiente auditivo ..." }\end{array}$ \\
\hline $\begin{array}{l}\text { 2. "E... agente.. a gente pede auxilio para alguns } \\
\text { colegas que falam LIBRAS"; Teve um aqui no balcão } \\
\text { a gente tinha um colega nosso que falava em } \\
\text { LIBRAS aí a gente chamava ele". }\end{array}$ \\
\hline $\begin{array}{l}\text { 3. "Eu acho bem legal quando eu atendo só que as } \\
\text { vezes ele chega sempre tímido, com medo e quando } \\
\text { eu faço algum sinal que ele sabe que vou entende-lo } \\
\text { na linguagem de LIBRAS já muda completamente a } \\
\text { expressão, ele fica mais receptivo ele se expressa } \\
\text { melhor". }\end{array}$ \\
\hline $\begin{array}{l}\text { 4. “...daí a gente se comunica via computador... digito } \\
\text { e escrevo e ele geralmente escreve”. }\end{array}$ \\
\hline $\begin{array}{l}\text { 5. "Geralmente a gente se comunica por papel.. } \\
\text { escrevendo"; "por conta da falta do conhecimento a } \\
\text { gente escreveu, eu escrevi ele escreveu mas deu } \\
\text { certo... poderia ter sido mais dinâmico, mas como } \\
\text { ninguém sabia nada a gente escrevia"; }\end{array}$ \\
\hline
\end{tabular}

Por ultimo foi perguntado se o funcionário faria o curso de LIBRAS se fosse oferecido e se ele teria alguma sugestão para melhorar o atendimento a pessoa surda? Muitas pessoas (9 participantes) responderam que fariam o curso e também que viam a necessidade e a importância dele, já 5 participantes disseram que fariam, mas colocaram a condicionante "tempo". Quanto as sugestões de melhoria, 8 entrevistados falaram que todos deveriam fazer o curso de LIBRAS, 2 falaram que seria importante ter um interprete de LIBRAS no aeroporto e 1 disse que poderia ter um atendente por turno que soubesse LIBRAS (tabela $5)$.

Tabela 5: Interesse em Fazer o Curso de LIBRAS

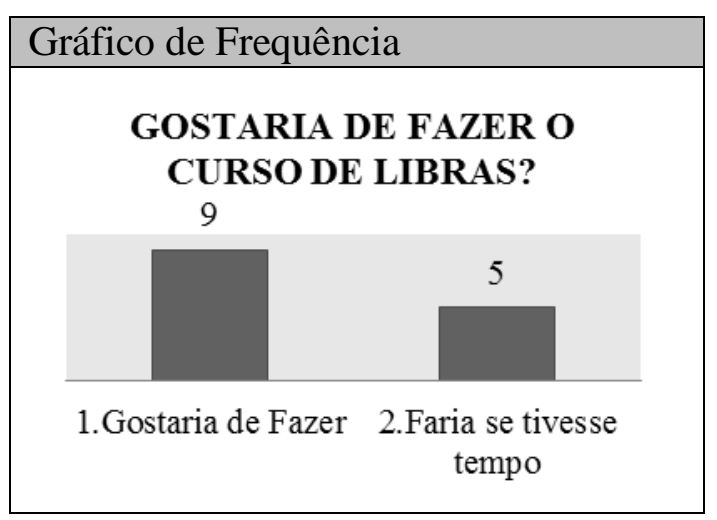

\begin{tabular}{|l|}
\hline Extrato Entrevista \\
"Se tivesse a opção, com certeza. Porque na verdade \\
até pra deixar eles mais a vontade, né? ; "Gostaria, \\
seria ótimo. No aeroporto a gente tem muito desses \\
passageiros e para atender a pessoa surda a gente \\
tem muita dificuldade e acaba constrangendo o \\
passageiro e acaba constrangendo a gente também \\
por trabalhar nesse local e não conseguir atender". \\
\hline 2."Se eu tivesse tempo disponível eu faria”; \\
"Depende do meu tempo, se tivesse tempo eu \\
realmente gostaria defazer";
\end{tabular}




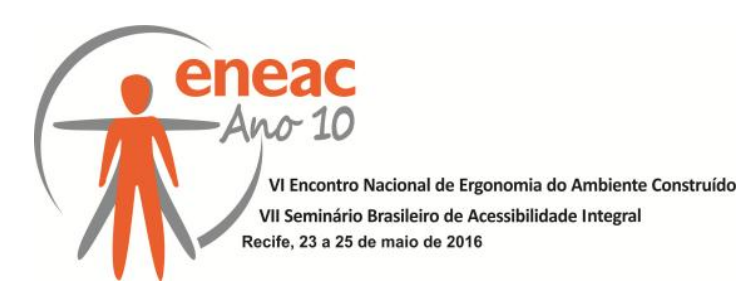

\section{DISCUSSÃO}

Com a interpretação dos dados coletados nesta pesquisa por meio da análise do conteúdo, constatou-se que a maioria (14 de 15) dos entrevistados já fizeram um atendimento a uma pessoa surda, e quase a totalidade deles utilizava recursos como a escrita em português (seja no papel ou no computador) para se comunicar, visto que o treinamento quando recebido era insuficiente para realizar um atendimento em LIBRAS. Durante as entrevistas era nítido o interesse de muitos dos funcionários em aprimorar esse atendimento, como pode ser visto na tabela 5 , onde 9 participantes afirmaram ter vontade fazer um curso de LIBRAS se houvesse a possibilidade. Já os outros 5 entrevistados acabaram colocando a condicionante "tempo" como algo que os impediria de fazer o curso, entretanto, é importante salientar que é possível estabelecer uma relação com os turnos de trabalho, uma vez que todos eles trabalham a noite ou de madrugada, tal fator deve ser levado em consideração na criação de um plano futuro para o atendimento a pessoa surda, levando em consideração o perfil do profissional que poderia fazer este atendimento.

Percebeu-se a importância do atendimento em Libras para os surdos que a utilizam, como pode ser visto no depoimento de um dos entrevistados, que havia feito um curso por inciativa própria, relatando: "Eu acho bem legal quando eu atendo só que as vezes ele chega sempre tímido, com medo e quando eu faço algum sinal que ele sabe que vou entende-lo na linguagem de LIBRAS já muda completamente a expressão, ele fica mais receptivo ele se expressa melhor".

A importância da valorização da Libras no atendimento ao surdo é indiscutível, no entanto é preciso levantar discussões junto a comunidade surda e as empresas a respeito de como poderia ser realizado esse atendimento, será que o caminho seria a contratação de Interpretes credenciados? Será que apenas um curdo de Libras oferecido aos funcionários é realmente suficiente? Será que a implementação de uma tecnologia de comunicação que fizesse a interface entre o surdo e o atendente seria uma solução viável? Desta forma, este trabalho, como uma investigação preliminar, teve a finalidade levantar essas questões.

\section{CONCLUSÃO}

Este artigo teve como objetivo verificar se os funcionários das companhias aéreas inseridas em um Aeroporto no sul do Brasil receberam treinamento adequado e estão aptos para atender o usuário surdo principalmente utilizando a Linguagem Brasileira de Sinais. Para tanto foram feitas entrevistas com gravação de voz com 15 funcionários dessas companhias aéreas, essas entrevistas foram transcritas e analisadas por meio da técnica de análise do conteúdo e pode-se constatar que a maioria dos atendentes não receberam treinamentos e os que receberam relataram o conhecimento era extremamente básico, como aprender a falar "bom dia, boa tarde e boa noite", o que não é suficiente para a comunicação com o usuário.

Com esse estudo foi possível perceber o interesse dos funcionários em fazer o melhor possível para atender a pessoa surda e por não ter treinamento suficiente eles se sentem constrangidos por não conseguirem realizar um bom atendimento, recorrendo a recursos como a escrita e os gestos. Algumas possibilidades de soluções foram levantadas pelos funcionários, como fazer um curso bem estruturado de LIBRAS, ou ter uma pessoa que tenha esse conhecimento em cada turno de trabalho.

É importante salientar que este estudo visou conhecer como está a situação do atendimento a pessoa surda nas companhias aéreas, mas explorou apenas o ponto de vista dos funcionários, assim como eles se sentem nessa situação. Para buscar soluções mais eficientes é preciso ouvir todos os envolvidos, principalmente os sujeitos surdos; este trabalho é uma pesquisa preliminar de exploração que faz parte da primeira etapa da dissertação de mestrado da pesquisadora, e teve o objetivo de levantar algumas discussões 


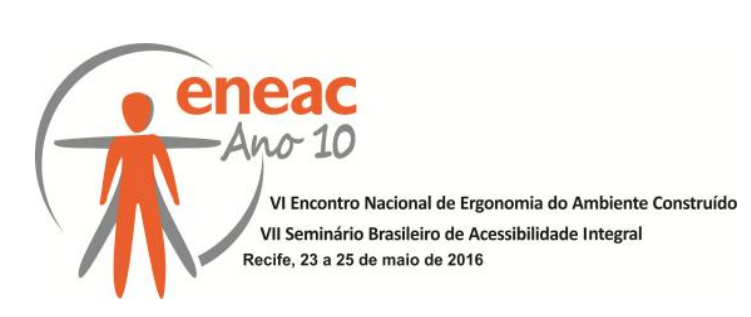

a respeito do problema colocado, é do entendimento da pesquisadora que para buscar soluções eficientes é preciso compreender todas as dinâmicas que tangem a situação, assim como todos os atores envolvidos no processo de atendimento (organização, funcionários e usuários).

\section{REFERÊNCIAS BIBLIOGRÁFICAS}

AZEREDO, Eduardo. Língua de Sinais: uma conquista histórica. Brasília - DF: Secretaria Especial de Editoração e Publicações - Senado Federal (Os:no 03747), 2006.

BARDIN, Laurence. Análise de conteúdo. 70. ed. Portugal, Lisboa: Persona, 1977.

CHAVEIRO, Neuma; BARBOSA, Maria. A. Assistência ao surdo na área de saúde como fator de inclusão social.Rev. esc. enferm. USP [online]. 2005, vol.39, n.4, pp. 417-422. ISSN 0080-6234. Disponível em: < http://www.scielo.br/pdf/reeusp/v39n4/06.pdf > Acesso setembro 2014.

CHAVEIRO, Neuma; BARBOSA, Maria. A; PORTO, C.C. Revisão da Literatura sobre o atendimento ao paciente surdo pelos profissionais da saúde. Rev. esc. enferm. USP [online]. 2008, vol.42, n.3, pp. 578-583. ISSN 0080-6234. Disponível em: < http://www.scielo.br/pdf/reeusp/v42n3/v42n3a22.pdf> Acesso setembro 2014.

FRANÇA, A.C.C.V.de. Interação Social de Pessoas Surdas no Cotidiano, Mediada por Sistemas de Produtos e Serviços de Comunicação. Dissertação (Mestrado), 254f, Programa de PósGraduação em Tecnologia, Universidade Federal do Paraná, Curitiba, 2011.

GOLDENBERG, M. A arte de pesquisar: como fazer pesquisa qualitativa em Ciências sociais. São Paulo: Record, 2003.

LABORIT, E. O vôo da Gaivota. São Paulo:Best Seller, 1994.

SILVA, Edna. L; Menezes, Estera.M. Metodologia da Pesquisa e Elaboração de Dissertação. 3ª ed. UFSC/PPGEP/LED -2001

SKLIAR, C. Bilinguismo e biculturalismo: uma análise sobre as narrativas tradicionais na educação dos surdos. Revista Brasileira de Educação, São Paulo, n.8, p. 44-57, maio-jun.-jul.-ago. 1998.

BRASIL. Decreto de lei № 5.626 Art.25 de 22 de dezembro de 2005. Disponível em: <file:///C:/Users/UFSC/Downloads/Decreto\%20no\%205626-LIBRAS regulamentacao\%20(1).htm> Acesso: julho, 2014. 